\title{
A cooperação federativa e a política de saúde: o caso dos Consórcios Intermunicipais de Saúde no estado do Paraná*
}

\author{
Federative cooperation and the health policy: \\ the case of Inter-municipal Health Consortiums in Paraná \\ Carlos Vasconcelos Rocha
}

\begin{abstract}
Resumo
0 objetivo deste trabalho é discutir e avaliar os elementos que têm dificultado ou facilitado a "cooperação horizontal" para a produção de políticas públicas na área da saúde. Especificamente, visa analisar os fatores que possibilitaram a difusão dos Consórcios Intermunicipais de Saúde no estado do Paraná. Tomando a institucionalização da cooperação federativa como uma forma de estabilização de regras e processos, a questão que orientará o trabalho é verificar como, ao longo do tempo, os atores, seus interesses e suas agendas de problemas têm incidido sobre a cooperação intermunicipal na produção da política de saúde.
\end{abstract}

Palavras-chave: relações intergovernamentais; descentralização; cooperação intermunicipal; políticas de saúde; consórcios de saúde.

\begin{abstract}
The objective of this paper is to discuss and evaluate factors that have hindered or facilitated a "horizontal cooperation" for the production of public policies in the area of health. Specifically, it aims to analyze the factors that enabled the dissemination of Inter-municipal Health Consortiums in the Brazilian state of Paraná. Viewing the institutionalization of federative cooperation as a way of stabilizing rules and processes, the question that will guide the study is to investigate how, over time, the actors, their interests and their problem agendas have focused on inter-municipal cooperation in the production of health policies.
\end{abstract}

Keywords: intergovernmental relations; decentralization; inter-municipal cooperation; health policies; health consortiums. 


\section{Introdução}

No Brasil, como forma de enfrentar os efeitos fragmentadores do processo de descentralização das políticas públicas, foram adotadas diversificadas experiências de cooperação intermunicipal para a produção compartilhada de múltiplas modalidades de políticas públicas. Tal tendência expressa uma tentativa de encontrar uma dimensão territorial "adequada" na produção de cada política pública específica, em contraste com a distribuição do poder federativo brasileiro entre o governo central, os estados e os municípios.

Nesse sentido, na área da saúde, foram desenvolvidas experiências de cooperação intermunicipal, com a difusão dos consórcios de saúde por todo o Brasil. 0 Paraná foi um dos estados brasileiros em que a difusão desses esquemas de cooperação foi mais significativa. Este trabalho pretende analisar os fatores que possibilitaram o desenvolvimento desse processo de reterritorialização na área de saúde no estado do Paraná, com a criação dos Consórcios Intermunicipais de Saúde (CIS).

Inicialmente o trabalho apresenta as características gerais da federação brasileira e a problemática envolvida na descentralização e na cooperação federativa. Posteriormente, serão expostas as características das políticas de saúde no Brasil, enfatizando seus aspectos federativos e territoriais. 0 surgimento dos CIS será ressaltado como uma das formas adotadas de cooperação intermunicipal na produção das políticas de saúde. Em seguida, serão apontados e discutidos os fatores que facilitam ou dificultam a cooperação intergovernamental, considerando o caso dos CIS no estado do Paraná. 0 trabalho se encerra com uma síntese das conclusões.

\section{A origem do problema: descentralização e cooperação federativa}

A discussão sobre a reforma do Estado brasileiro, que entrou na agenda política do País a partir da década de 1980, colocou em relevo o tema da descentralização. Como reação ao regime autoritário, caracterizado pela concentração de poder no governo central e por uma tendência à organização hierárquica das relações federativas, diversos setores da sociedade brasileira passaram a reivindicar a descentralização político-administrativa como forma de adequar o desenho das instituições públicas aos requisitos de uma democracia. Em termos federativos, esse movimento visou fortalecer a autonomia de estados e municípios em reação ao "federalismo nominal" característico do período autoritário, baseado na centralização do poder no governo federal. Nesse sentido, com a Constituição Federal de 1988, o Brasil avançou a construção de um federalismo "de fato". 0 poder foi redistribuído em favor dos estados, do Distrito Federal e dos municípios - hoje 27 estados, incluso o Distrito Federal, e 5.565 municípios $^{1}$-, que passaram a ser definidos como entes da federação, configurando um federalismo tripartido.

No plano normativo, a descentralização difundia-se como uma panaceia para todos os males, sendo relacionada a uma multiplicidade 
de objetivos e significados, segundo os interesses e valores de diversos atores distribuídos pelo espectro ideológico nacional. Para os setores mais à esquerda, a descentralização era vista como uma estratégia de democratização tanto política como social; para os setores mais à direita, era tomada como uma estratégia de racionalização técnico-administrativa, visando alcançar maior eficiência nas ações públicas.

Essa crença inicialmente difundida se desdobrou, em seu aspecto federativo, na concepção de que os municípios deveriam resolver da forma mais autônoma possível os seus problemas, resultando no que Daniel (2001, p. 14) denominou "municipalismo autárquico". Tal concepção instaura as bases de um federalismo competitivo, no qual há poucos incentivos para que os municípios estabeleçam ações cooperativas.

Contudo, ao longo da implementação dessas reformas, a experiência mostrou que elas podem gerar resultados opostos aos esperados. No caso brasileiro, a grande maioria dos municípios padece de precariedade técnica, administrativa e financeira. Nesse contexto, a descentralização tende a fragilizar ainda mais a provisão de serviços estatais, por repassar prerrogativas para municípios sem condições de exercê-las integralmente e por fragmentar as ações públicas de forma a comprometer uma escala adequada da oferta de serviços. Ademais, como se sabe, a superação ou minimização das desigualdades regionais existentes no Brasil exige a adoção de mecanismos de coordenação federativa e de fomento à cooperação intergovernamental, além da implementação de políticas compensatórias em favor dos entes mais necessitados (Arretche, 1996).
Resulta que, com a descentralização, foi se afirmando a necessidade de maior coordenação federativa na produção das políticas públicas, tanto em seu sentido vertical, articulando União, estados e municípios, como, também, em seu sentido horizontal, estruturando esquemas de cooperação entre estados e, principalmente, entre municípios. Mostrou-se indispensável, portanto, produzir relações mais complexas e matizadas entre os entes federados.

Assim, como se reconhece amplamente hoje, o processo de reforma do Estado, notadamente em federações, requer o equacionamento de graus e mecanismos diversificados de centralização e descentralização. Esse balanço não pode ser definido a priori e de forma abstrata, pois exige um amplo aprendizado e alguma criatividade dos atores sociais. ${ }^{2}$ Demanda uma articulação de funções e um compartilhamento de recursos entre os níveis de governo, de maneira a se criarem condições propícias à democratização e à ampliação da eficácia e da eficiência das políticas públicas, antes vistas como efeitos diretos da descentralização.

Como resultado desse aprendizado por diversos atores envolvidos no processo de reforma do Estado brasileiro, diversas modalidades de cooperação federativa surgiram. Especificamente, no plano horizontal, foram instituídas câmaras, redes, agências, associações, fóruns, empresas e autarquias intermunicipais (Cruz, 2001; Abrucio e Soares, 2001). No entanto, a experiência mais relevante de ação cooperativa horizontal foi a dos consórcios intermunicipais, notadamente aqueles relacionados com a provisão de bens e serviços na área da saúde. 
A viabilização da cooperação intermunicipal para a produção de políticas públicas não é, no entanto, algo trivial. Requer, no seu aspecto territorial, a definição de novos padrões de regionalização que, no caso dos CIS, são supramunicipais. A cooperação, no caso, demanda uma recriação do desenho territorial do federalismo tripartido brasileiro, baseado na União, nos estados e nos municípios.

Esse esforço de remapeamento encontra obstáculos de diversas naturezas. Os municípios, como entes federados, são, em última instância, autônomos para adotar, ou não, esquemas cooperativos em diversas áreas nas quais são detentores de prerrogativas. Se, por um lado, pelos requisitos técnicos da produção de políticas públicas, encontram incentivos para a cooperação (visando ganhos de escala, por exemplo), por outro, são impelidos a competir, no contexto federativo, em diversos aspectos, especialmente na esfera político-eleitoral. ${ }^{3}$

Essa problemática da cooperação federativa incita um amplo debate. Nesse sentido, o estudo de caso aqui proposto faz emergir duas questões. A primeira, que será desenvolvida neste artigo, diz respeito aos fatores que facilitam ou dificultam a cooperação intergovernamental. A segunda, desenvolvida em Rocha e Castro (2015) - e sinteticamente exposta neste trabalho -, refere-se aos motivos pelos quais determinados padrões de regionalização são adotados no contexto da cooperação intermunicipal.

Antes de desenvolver a análise do problema proposto, no tópico seguinte serão apresentadas as características das políticas de saúde no Brasil, enfatizando seus aspectos federativos e territoriais.

\section{Políticas de saúde \\ e o desafio da regionalização: contextualizando o surgimento dos CIS}

Com a Constituição Federal de 1988, momento de consolidação do processo de democratização política no Brasil, foi adotado um Sistema Único de Saúde (SUS) inspirado no National Health Service, da Inglaterra, fundado nos princípios da universalidade, equidade, integralidade, com gestão descentralizada e participativa. A tentativa de reproduzir esse modelo numa federação - em comparação a um país unitário como a Inglaterra - reveste-se de especial complexidade: no caso, na produção das políticas públicas a questão sobre "quem deve fazer" se sobrepõe à de "o que fazer" (Pierson, 1995). Ainda mais no caso do sistema público de saúde brasileiro, um dos maiores do mundo em termos de número de usuários e com responsabilidades divididas entre os três níveis de governo. Os desafios colocados para a estruturação dessa política são, portanto, imensos.

Coerente com o princípio da descentralização federativa - tomado como meio de democratização e de eficiência na gestão pública -, o primeiro decênio da implantação do SUS priorizou a municipalização da saúde. Instaurou-se, assim, um processo de intensa transferência de competências e recursos, antes concentrados no governo central, em direção aos municípios, através de instrumentos normativos como as Normas Operacionais Básicas (NOB) e as Normas Operacionais de Assistência à Saúde (Noas), utilizados pelo Ministério da Saúde para estruturar o setor. 
Sendo assim, os municípios passaram a assumir progressivamente a gestão dos serviços de saúde em seus territórios.

À medida que a descentralização ia se consolidando, essa ênfase no papel dos municípios começou, no entanto, a demonstrar os problemas que foram expostos genericamente no tópico anterior. Primeiramente, a heterogeneidade de capacidades financeiras e administrativas dos municípios para assumirem a gestão da saúde acabou conflitando com o princípio da equidade. Além disso, instaurou-se uma tensão entre a lógica da descentralização e os requisitos técnicos do sistema de saúde. Em outras palavras, essa tensão se deve ao fato de que a descentralização responde ao objetivo político de afirmação da autonomia dos estados e municípios, ao mesmo tempo que a lógica da política de saúde demanda um funcionamento coordenado de relações intergovernamentais visando cumprir os objetivos sistêmicos de universalidade, equidade e integralidade.

A fragmentação territorial resultante da afirmação das prerrogativas políticas dos municípios como gestores da saúde acabou, portanto, contraditando os princípios do SUS, por demandar outro tipo de organização territorial. Um aspecto dessa inadequação, por exemplo, revela-se no fato de que, no sistema único e universal de saúde do Brasil, as fronteiras político-geográficas não delimitam o fluxo de pacientes, já que cobrem todo o território e toda a população, ao passo que a oferta dos serviços é fragmentada pelas unidades político-administrativas.

Nesse sentido, foi ficando cada vez mais clara a necessidade da configuração de arranjos cooperativos visando remapear 0 federalismo tripartido brasileiro na área das políticas de saúde. Prover os serviços para a população requer, portanto, um planejamento que considere uma escala adequada de oferta dos serviços. Isso demanda uma territorialidade que pode abranger vários municípios, mais de um estado ou mesmo partes de municípios. Daí a necessidade de acordos políticos para a institucionalização de formas de cooperação horizontal e vertical entre os entes federados.

$\mathrm{Na}$ verdade, a consciência da necessidade dessa regionalização existia antes do surgimento dos efeitos fragmentadores da descentralização: esse pressuposto técnico era parte de um estoque de conhecimento compartilhado há muito tempo, pois constitutivo, por exemplo, do modelo de saúde da Inglaterra, inspirador do SUS. No plano da formulação da reforma da saúde, já havia a convicção de que a demarcação territorial na produção da política deveria adotar a concepção estratégica de distritos sanitários, como denota uma resolução da VIII Conferência Nacional de Saúde, ${ }^{4}$ realizada ainda em 1986 (Keinert, 2001, p. 21). Consagrando essa concepção, o princípio da regionalização foi inscrito na Constituição Federal de 1988 como mecanismo da descentralização, integralidade e hierarquização da saúde. Tal princípio se desdobrou em toda uma legislação derivada. Por exemplo, a Lei Orgânica da Saúde n. 8080/1990 afirmava a necessidade da regionalização como princípio de organização do sistema, mas não aprofundava seu significado, aspecto que, naturalmente, não foi efetivado. Posteriormente, a Norma Operacional de Assistência à Saúde (Noas) - SUS 1/2001 propunha a criação de regiões de saúde, só que de maneira formalista e rígida, sem resultar em avanços significativos. Em 2006, o Pacto pela 
Saúde, composto por um conjunto de portarias, foi mais realista, procurando induzir os entes federados a estabelecerem pactos visando à adoção de "regiões de saúde", de gestão intergovernamental regional e de planejamento conjunto. Apesar de ter tido significativa adesão dos municípios, isso ocorreu mais no plano da formalidade. Ainda nessa linha, através do Decreto 7.508/2011, o Ministério da Saúde adotou o Contrato Organizativo da Ação Pública (Coap), visando induzir acordos de colaboração firmados entre os três entes federativos, no âmbito de uma Região de Saúde, com o objetivo de organizar e integrar as ações e os serviços de saúde e garantir a integralidade da atenção à saúde da população no território (Viana et al., 2008; Santos e Andrade, 2009; Lima et al., 2012).

Tais tentativas tiveram, por motivos variados, resultados práticos muito limitados. Especificamente, nas décadas de 1980 e 1990, a regionalização tinha um relevante obstáculo de natureza política. Enquanto o governo federal buscava, num crescendo, induzir a regionalização da saúde através de ampla legislação, os municípios procuravam afirmar a sua autonomia, com o respaldo da Constituição. Esse movimento contraditório fez com que as tentativas do governo central de organizar a regionalização da saúde não alcançassem seus objetivos. $\mathrm{Na}$ outra ponta, os municípios interpretavam essas tentativas como ameaça a sua almejada autonomia. Essa distância entre o normativo e o efetivo é expressão de uma tensão entre os requisitos técnicos de uma política pública e os imperativos da política, que é uma questão que baliza toda a problemática da cooperação intergovernamental. ${ }^{5}$ Em outros termos, ocorre que "uma visão estritamente normativa sobre o sistema de saúde é facilmente contestada pelo território usado, isto é, pelo território vivo" (Viana et al., 2008, p. 94).

Dadas essas dificuldades, um efetivo processo de regionalização só vai surgir em meados dos anos de 1990, com a difusão dos CIS, por alguns fatores conjugados. De um lado, os mecanismos indutores da cooperação vão paulatinamente se fortalecendo, por parte tanto do governo central como dos estados, fruto do aprendizado acumulado por esses entes e do convencimento da sua necessidade. De outro lado, do ponto de vista dos municípios, num contexto de crise econômica e de restrições fiscais, nos anos de 1980 e 1990, a incapacidade de fornecer respostas individuais às pressões do eleitorado por acesso aos serviços de saúde induz à consciência de que diversos problemas de gestão só poderiam ser equacionados de forma cooperativa. Além do reconhecimento dessa incapacidade, nesse momento um requisito político para a cooperação estava dado: a ênfase na "distribuição de poder", que diz respeito à afirmação da autonomia dos municípios como forma de superar a centralização federativa do regime autoritário, encontrava-se relativamente resolvida. Com suas garantias de autonomia satisfatoriamente consolidadas, já que arrefecidos os conflitos em torno da "distribuição" do poder federativo - questão prioritária ao longo da democratização -, os municípios podiam concentrar-se nos requisitos técnicos necessários para a produção de políticas públicas de maior qualidade. A lógica aí envolvida é expressa por Scharpf (1988), ao dizer que "eficiência e flexibilidade são subordinadas às garantias procedurais de acomodação política" (apud Pierson, 1995, p. 459). ${ }^{6}$ As políticas que visam garantir dois objetivos, 
metas substantivas e proteção de posições institucionais, tendem a ser menos efetivas do que as que visam apenas ao primeiro objetivo.

Como salientado anteriormente, dentre as variadas modalidades de cooperação federativa, os consórcios intermunicipais foram das mais relevantes. Os consórcios intermunicipais constituem uma forma de associação ou união entre municípios, calcada na percepção de um compartilhamento de interesses e propósitos, articulados nos mais diferentes âmbitos, visando ao provimento de serviços públicos como tratamento e destinação do lixo, cultura, lazer, educação e merenda escolar, além da realização de obras públicas, agricultura e desenvolvimento sustentável (Cruz, 2001; Vaz, 1997).

Um Consórcio Intermunicipal de Saúde (CIS), por sua vez, é a união ou associação de dois ou mais municípios visando à resolução de problemas e à busca de objetivos comuns no setor, mediante a utilização conjunta dos recursos humanos e materiais disponíveis (Brasil, 1997, p. 10).

A difusão dos CIS teve início em meados dos anos de 1990 em alguns estados brasileiros. Esse processo se deu de forma heterogênea, pois dependeu, em grande medida, das características políticas específicas dos estados, variável explicativa relevante para a difusão da cooperação, como será tratado a seguir. Dois dos casos de maior sucesso foram dos estados de Minas Gerais e do Paraná, este último objeto dos próximos tópicos. ${ }^{7}$

\section{0 caso do Paraná: algumas reflexões exploratórias acerca das possibilidades de cooperação intermunicipal}

O estado do Paraná, localizado na região Sul, é um dos 27 estados brasileiros (incluindo o Distrito Federal). É o $15^{\circ}$ em dimensão territorial, o $6^{\circ}$ em população, com cerca de 11 milhões de habitantes, e tem $05^{\circ}$ maior PIB do País. 0 estado tem 399 municípios, conforme demonstra o Mapa 1.

No Paraná, a partir do início de 1990, foram constituídos progressivamente 26 CIS (ver Anexo I). As primeiras experiências se desenvolveram nos municípios pequenos do norte e nordeste do estado, com estruturas administrativas precárias, e, posteriormente, se difundiram para a quase totalidade do estado. Hoje, dos 399 municípios, 390 integram pelo menos um CIS. Ou seja, 97,5\% dos municípios paranaenses estão consorciados, com uma média de 16 por consórcio. 0 menor tem três municípios e o maior tem 30.

Em relação ao conjunto dos CIS, é necessário apontar algumas peculiaridades. Dos 26 CIS, o Consórcio Paraná Saúde é atípico. Congregando 394 municípios, ele reproduz quase que perfeitamente o padrão de territorialização do próprio estado, tendo como único objetivo comprar e distribuir medicamentos entre os seus integrantes. Ao contrário, todos os outros CIS 


\section{Mapa 1 - Estado do Paraná e municípios}

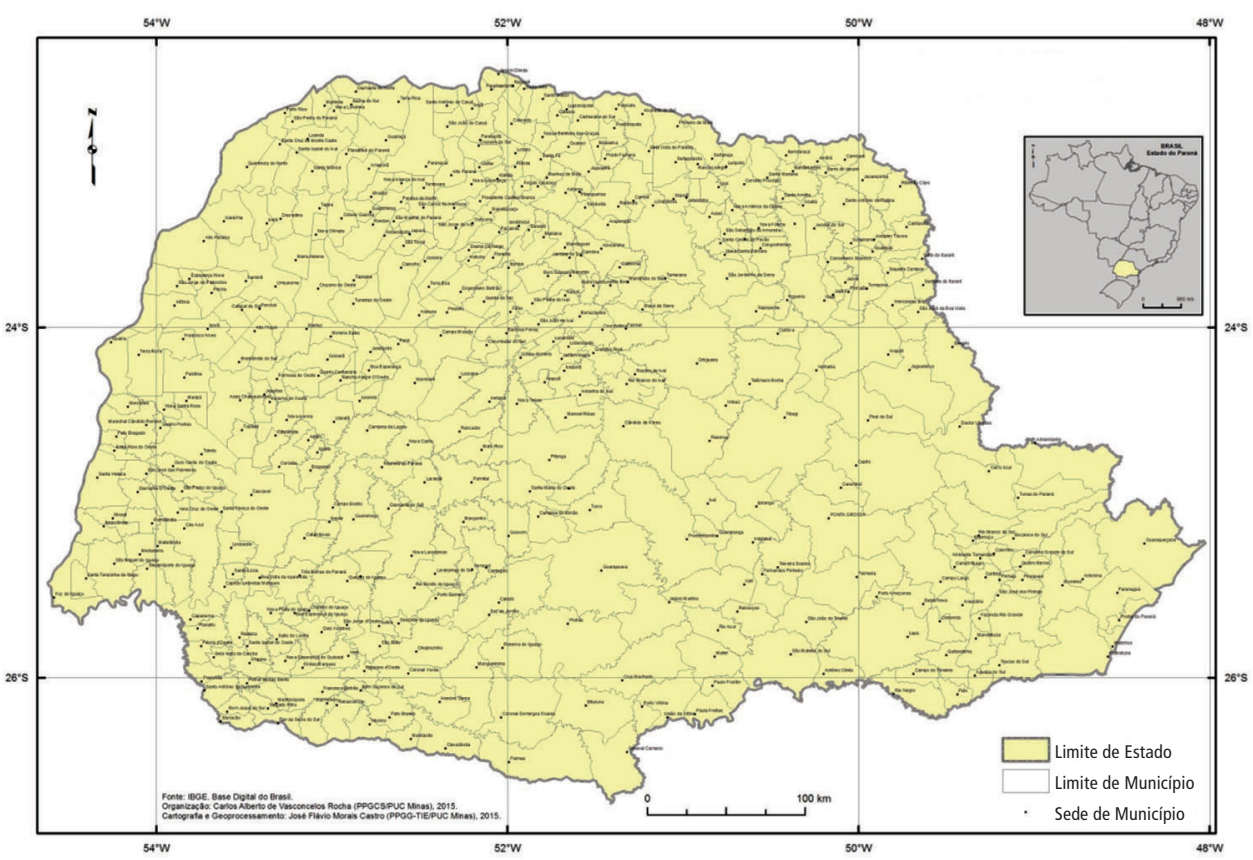

Fonte: Mapa elaborado pelo prof. dr. José Flávio Morais Castro, da PUC Minas.

\section{Mapa 2 - Consórcios Intermunicipais de Saúde (CIS) do Paraná}

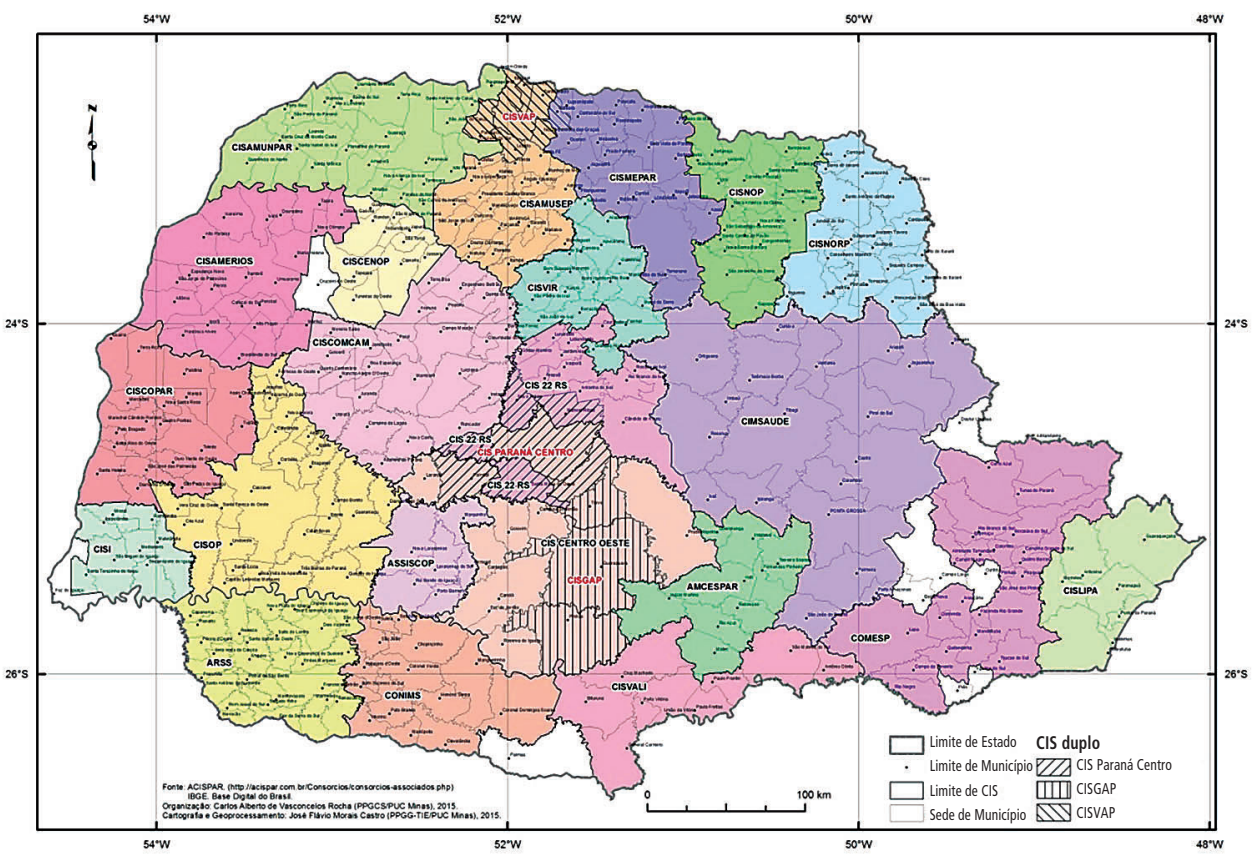

Fonte: Mapa elaborado pelo prof. dr. José Flávio Morais Castro, da PUC Minas. 
definem formas de regionalização mais restritas e buscam fornecer um amplo leque de serviços.

0 Cislipa também é específico, pois suas funções são bastante limitadas se comparadas com as dos outros CIS. Seu objetivo é compartilhar o Serviço de Assistência Médica de Urgência (Samu), que visa fornecer transporte e primeiros socorros para casos de urgência. Esse CIS está localizado no entorno da Região Metropolitana de Curitiba, que é a região com maior concentração de população e recursos econômicos do estado, características que desestimulam a cooperação, conforme será desenvolvido adiante.

Além disso, há 18 municípios que participam de mais de um CIS, configurando consórcios sobrepostos no território. É o caso do Cisvap, do CIS Paraná Centro e do Cisgap, que se encontram com hachuras no Mapa 2. Por sua vez, o Conins tem sete de seus 20 municípios pertencentes ao estado vizinho de Santa Catarina, ${ }^{8}$ o que o torna especialmente complexo, pois o CIS se relaciona com dois governos estaduais simultaneamente.

A criação dos CIS envolveu uma lógica política, permeada por conflitos e consensos, dependente, em última instância, de acordos entre os prefeitos, o que é evidenciado pelo largo período de tempo que perpassou sua difusão pela quase totalidade dos municípios do estado, conforme demonstra o Quadro 1.

São diversas as explicações para esse processo. A seguir, serão desenvolvidas algumas considerações sobre os fatores - que se entrelaçam - que facilitaram ou dificultaram o consorciamento no estado.

\section{Quadro 1 - CIS por ano de implantação}

\begin{tabular}{|l|l|}
\hline Ano & CIS \\
\hline 1992 & 1 \\
1993 & 3 \\
1994 & 1 \\
1995 & 5 \\
1996 & 3 \\
1997 & 3 \\
1998 & 4 \\
1999 & 1 \\
2002 & 1 \\
2009 & 1 \\
2010 & 2 \\
2014 & 1 \\
\hline
\end{tabular}

Fonte: Elaboração própria a partir de dados da Acispar (s/d); Lima (1998) e Paraná (2009). 


\section{A cooperação como resultado da ação dos policy entrepreneurs e do movimento sanitário}

A constituição dos CIS, no Paraná, resultou de um processo de aprendizado envolvendo políticos, técnicos e setores da sociedade civil, como prefeitos, secretários municipais e estaduais de saúde, técnicos da Sesa e dos municípios, movimentos de profissionais da área da saúde e partidos políticos. Atuando dentro de contextos específicos, ao longo do tempo, os atores envolvidos teceram relações horizontais, conectando municípios, e verticais, articulando municípios com o âmbito estadual. Em grau relevante, desenvolveram uma teia de relacionamentos, muitas vezes informais, que vitalizou a dimensão formal dos CIS. Além das regras pactuadas que orientam a cooperação, desenvolveram uma confiança, principalmente entre as burocracias municipais e estadual, exercitada no trato frequente das questões relativas à gestão da saúde, o que remete ao importante aspecto da construção de capital social, que diz respeito "a características da organização social, como confiança, normas e sistemas que contribuam para aumentar a eficiência da sociedade, facilitando as ações coordenadas" (Putnam, 1996, p. 177).

Especificamente, alguns personagens especiais foram fundamentais na difusão dos esquemas de cooperação. Técnicos com profunda dedicação à causa da saúde pública, com capacidade de articulação política, mediaram as relações entre autoridades municipais de partidos variados, buscando convencê-las da relevância da cooperação para a produção das políticas públicas (Laczynski e
Teixeira, 2012; Rocha e Faria, 2004). No limite, faziam política através de um discurso técnico, difundindo ideias elaboradas coletivamente em diversos âmbitos, cristalizadas principalmente nas Conferências Nacionais de Saúde. Portanto, eram portadores de concepções sobre como estruturar as políticas de saúde e trabalhavam para concretizá-las.

Tais personagens podem ser classificados como policy entrepreneurs. Conforme exposto por Mintrom,

Os policy entrepreneurs podem ter um papel fundamental na identificação de problemas relacionados com as políticas públicas, de modo que tanto atraem a atenção dos decision makers como indicam respostas apropriadas às políticas. Os policy entrepreneurs devem desenvolver estratégias para apresentar suas ideias para os outros. É por isso que eles gastam tanto tempo intercomunicando-se "dentro" e "em torno" do governo. Assim fazendo, eles captam a "visão de mundo" de vários membros da policy-making community e tecem contatos que os ajudam a afirmar a sua credibilidade. Fazer esses contatos permite que possam determinar quais argumentos irão persuadir os outros para que apoiem suas ideias. ${ }^{9}$ (1997, p. 739)

Esses policy entrepreneurs surgem no contexto de um movimento coletivo mais amplo, de âmbito nacional, que foi o movimento dos sanitaristas. 0 Movimento Sanitário, que surgiu no Brasil nos anos de 1970, era composto especialmente por profissionais da saúde com o objetivo de defender a saúde pública como direito universal, e se baseava nos princípios de integralidade, equidade e descentralização. Além de constituir um movimento social 
com a característica clássica de direcionar demandas ao Estado, através de um leque de estratégias de pressão, os sanitaristas procuraram também desenvolver sua atuação nos partidos políticos - quase sempre de esquerda - e ocupar cargos governamentais. Como autores de ideias sobre a reformulação do sistema de saúde brasileiro, atuaram também em universidades, desenvolvendo pesquisas e formando profissionais. ${ }^{10}$ Considerando o caso do Paraná, são vários os exemplos da atuação desses personagens, como será apontado à frente.

A constituição dos CIS teve origem em ações desenvolvidas tanto no plano estadual como no plano dos municípios. Num primeiro momento, a cooperação intermunicipal foi obra de atores que atuavam no âmbito dos municípios; posteriormente, o papel indutor dos governos estaduais foi fundamental. Em ambos os níveis, no entanto, a presença dos policy entrepreneurs foi decisiva.

Como se disse, direta ou indiretamente esses agentes são forjados no movimento sanitarista, constituído na sociedade civil com o objetivo de articular demandas ao Estado. No entanto, o impacto das suas ações se potencializa quando eles passam a compor a burocracia estatal ou a assumir posições de mando nos governos. A necessidade dos governos estaduais e municipais de estruturarem a área da saúde através do recrutamento de técnicos preparados coloca em relevo os participantes do movimento sanitário, que forneciam uma concepção elaborada sobre um modelo de organização do setor.

No plano do estado, a partir de 1983, os governos estaduais consecutivos do PMDB (José Richa, Álvaro Dias e Roberto Requião), partido que abrigava um amplo contingente de sanitaristas nos seus quadros, passaram a recrutar equipes técnicas multiprofissionais para a Sesa, que foram distribuídas pelo território do Paraná. Esses técnicos cumpriram um papel fundamental no enfrentamento da situação de carência de estrutura de oferta de serviços de saúde, especialmente por parte dos municípios menores. Seja pela formação anterior, no âmbito das universidades ou dos movimentos sociais, seja pelo esforço do próprio poder público em qualificar seus funcionários, esses profissionais difundiam as ideias forjadas pelo movimento sanitário.

Por exemplo, os técnicos que entravam para a Sesa tinham que fazer um curso intensivo de três meses, de 40 horas semanais, em centros cuja orientação se baseava nos princípios do pensamento sanitarista. Essas pessoas estavam, em grande parte, alocadas nas Regionais de Saúde (RS) da Sesa, ${ }^{11}$ quando se desenvolve o processo de implementação do SUS. Criou-se, assim, uma massa crítica de técnicos, distribuídos por todo o território do estado, que utilizavam as RS como suporte para suas ações, conectando o governo estadual com conjuntos de municípios, que compartilhavam das mesmas ideias e que, no futuro, teriam um papel crucial na criação dos CIS.

No plano dos municípios, esse processo teve também os seus desdobramentos. Devido à precariedade técnica de grande parte das administrações municipais, no sentido de cumprir a sua recente prerrogativa de gerir os serviços de saúde, vários prefeitos passaram a recrutar esses atores para cargos de direção na área da saúde (Dowbor, 2014). Assim, técnicos dedicados à causa da saúde pública, com alta capacidade de articulação política, passaram a ocupar espaços na burocracia e em cargos de 
direção nos governos municipais. Levaram, portanto, para os espaços de tomada de decisões suas convicções sobre a política de saúde e, especificamente, sobre a relevância da cooperação intermunicipal para estruturar essa política setorial (Laczynski e Teixeira, 2012; Rocha e Faria, 2004). Nesse caso, privilegiavam a atuação nas Associações de Municípios (AMs), ${ }^{12}$ visando convencer os prefeitos a estenderem a cooperação para a área da saúde.

Portanto, o processo de criação dos CIS envolveu a ação dos atores em duas dimensões: no âmbito dos municípios - especialmente dos menores - e no do estado, através do seu papel indutivo. Nos tópicos seguintes serão expostas essas dimensões.

\section{As experiências pioneiras de Consórcios Intermunicipais de Saúde: uma estratégia capitaneada pelos municípios menores}

A experiência do Brasil, em geral, e do Paraná, em particular, parece corroborar a tese de que municípios pequenos encontram maior necessidade de cooperação (Cruz, 2001, p. 12), seja em função da maior dificuldade de resolução de seus problemas, devido à sua maior carência de recursos financeiros e administrativos, seja pela necessidade de potencializar sua capacidade de negociação com os outros entes, já que tendem a ter menor poder de barganha ante os governos estaduais e federal. No Brasil, nos primeiros anos de implantação dos CIS, $60 \%$ dos municípios consorciados possuíam menos de 10.000 habitantes, enquanto somente 5,5\% tinham uma população superior a 50.000 habitantes. No caso do Paraná, dos municípios que faziam parte de CIS, até o ano 2000, predominavam aqueles com população de até $50 \mathrm{mil}$ habitantes (Lima e Pastrana, 2000, p. 9).

Segundo o Ministério da Saúde, para os municípios de pequeno porte, o CIS viabiliza a oferta de um atendimento de melhor qualidade e de maior complexidade à sua população. Oferecer serviços de saúde em todos os níveis representa, para a maioria dos municípios, encargos superiores à sua capacidade financeira. Esses municípios são incapazes de ofertar certos serviços por problemas de escala. A prestação de serviços de forma regionalizada evita a sobrecarga do município na construção de novas unidades de oferta de serviços ambulatoriais e hospitalares, na contratação de recursos humanos especializados e na aquisição de equipamentos de custos elevados. 0 CIS possibilita, ainda, uma utilização mais racional da rede disponível (Brasil, 1997; Diniz Filho, 2006).

Mendes caracteriza bem esse primeiro momento, em que as iniciativas surgem no nível dos municípios:

a crescente fragilidade das secretarias estaduais de saúde fez com que elas fossem, gradativamente, retirando-se da prestação de serviços secundários e terciários ou tornando esses serviços de tão baixa qualidade, que obrigou os municípios a suprir essas deficiências dos sistemas. [...] Os Consórcios Intermunicipais surgem espontaneamente das necessidades dos municípios em resolver problemas e não como resultado de políticas nacionais ou estaduais deliberadas. (1996, p. 287)

No caso do Paraná, na criação dos primeiros CIS, as iniciativas vieram de policy entrepreneurs que atuavam no âmbito dos municípios do norte e noroeste do estado - região composta majoritariamente por pequenos 
municípios -, através do convencimento de autoridades municipais da necessidade de cooperarem na gestão da saúde. As características dessas regiões explicam de certa forma a busca de ações cooperativas. Os municípios do norte e noroeste se caracterizam, historicamente, pelo relativo atraso econômico e administrativo em relação aos municípios do litoral, implicando precariedades derivadas de carências de recursos e, portanto, dificuldade de fornecer respostas individuais aos seus problemas. Resta, dessa forma, a cooperação como forma de enfrentar essa situação de fragilidade dos municípios.

Desse esforço inicial, foram criados os primeiros CIS: Cisamunpar, com sede em Paranavaí, com 28 municípios; Ciscomcam, com sede em Campo Mourão, com 25 municípios; Cisamerios, com sede em Umuarama, com 21 municípios; e Cismepar, com sede em Londrina, com 21 municípios. Em cada um desses casos e, em geral, no caso de todos os CIS - fica muito clara a presença desses policy entrepreneurs, que compartilhavam algumas características: faziam parte do movimento sanitarista; tinham algum contato com os centros de produção de ideias, como universidades, Conferências de saúde e associações profissionais da área; tinham algum tipo de envolvimento na política partidária, visando implementar suas ideias sobre as políticas de saúde; eram parte da burocracia da saúde e/ou ocupavam cargos de direção no estado ou em municípios.

Criados os primeiros CIS, instaurou-se um movimento mimético que envolveu um processo acumulativo em que cada um que se constituía incentivava a criação de outros. Em cada novo CIS que surgia, a rede de apoio e de difusão de ideias se afirmava na reprodução de outros consórcios, instaurando um processo de aprendizado envolvendo tanto políticos como técnicos. Nesses spillover effects, a fórmula adotada por alguns conjuntos de municípios era avaliada como promissoras, o que fortalecia o discurso dos policy entrepreneurs e, consequentemente, convencia mais políticos das vantagens de repeti-la (Kingdon, 1995).

Assim, os CIS são criados tomando como referência esquemas de cooperação anteriormente constituídos que tiveram êxito. Na verdade, a experiência pioneira de cooperação intermunicipal na área da saúde, no Brasil, ainda no início da década de 1980, é a de Penápolis, município do estado de São Paulo, onde um prefeito, que era enfermeiro, reuniu diversos municípios para gerir uma Santa Casa que se encontrava em grande dificuldade. Vários gestores municipais de saúde do Paraná, quando da articulação dos CIS, tinham como referência inicial essa experiência inovadora.

Essa maior propensão de cooperação entre municípios menores pode ser evidenciada por exceções que confirmam a tendência. No caso do Cismepar, Londrina, na época o maior município brasileiro participante de um CIS, com aproximadamente 412 mil habitantes (Lima, 2000, p. 988), articulou a cooperação com seus municípios vizinhos, todos de pequeno porte, muito pelo papel da Faculdade de Medicina localizada em seu território, em que havia uma forte militância sanitarista, cujos membros atuaram no sentido de estruturar consórcios em toda a região.

No caso do Cisamunpar, Paranavaí, um município com cerca de 75 mil habitantes, resiste consorciar com municípios vizinhos, todos com menos de 5 mil habitantes. No entanto, acaba cedendo pela pressão exercida pelos 
membros da AM da região - do qual era um dos integrantes - que, em votação visando decidir sobre a criação de um CIS, derrotam Paranavaí por 27 a 1, o que leva o município a participar do consórcio.

Considerando os municípios não consorciados, ou aqueles que se consorciaram tardiamente devido a pressões do governo estadual, a mesma lógica permanece. A Região Metropolitana de Curitiba, e seu entorno - justamente por ser aquela em qual a oferta de serviços é comparativamente maior e a estrutura de transporte permite fácil mobilidade no seu território -, é onde se concentra a quase totalidade de municípios não consorciados, ou seja, seis municípios do total de nove. Ademais, sintomaticamente, foi a última região do estado em que os CIS se difundiram: o Cislipa, o Comesp e o Cimsaúde começaram a funcionar depois de 2010 (Paraná, 2009; Lima, 1998). $\mathrm{Na}$ verdade, Curitiba formou um consórcio, o Comesp, por indução do governo estadual. Além disso, como notado anteriormente, o Cislipa tem funções limitadas, qual seja, a de gerir o Serviço de Assistência Médica de Urgência (Samu).

Dentre os três municípios não consorciados que se encontram fora da Região Metropolitana, pelo menos um, Foz do Iguaçu, também é um caso de município que não tem incentivo para a cooperação, pois é dotado dos requisitos para gerir de forma mais autônoma a sua política de saúde. Com a sétima população dos municípios do estado (cerca de 270.000 habitantes), Foz do Iguaçu é o segundo destino de turistas no Brasil, contando, portanto, com fonte de renda significativa, além de ser servido por um grande hospital da Usina Hidrelétrica de Itaipu. ${ }^{13}$
Em cena o governo estadual: o papel da indução na formação dos Consórcios Intermunicipais de Saúde

Se, num primeiro momento, os CIS foram criados por iniciativa de atores no âmbito de alguns municípios, posteriormente, irão se difundir devido ao papel indutor dos governos estaduais.

Na década de 1990, com o processo de municipalização da saúde, as secretarias estaduais entraram em crise de identidade, já que o governo federal passou a se relacionar diretamente com os municípios. Houve, portanto, uma fragmentação na produção das políticas de saúde, na medida em que os municípios passaram a ser vistos como unidades gestoras do setor.

Como uma das formas de retomar um papel relevante na política de saúde, os governos estaduais buscaram exercer a coordenação das ações municipais. Em grande medida, isso foi feito a partir da constatação de que os municípios individualmente não dariam conta de fornecer serviços de saúde compatíveis com as demandas de suas populações. Alguns governos estaduais, em geral, e o do Paraná, especificamente, passaram, assim, a desenvolver mecanismos de indução para a cooperação intermunicipal nas ações de saúde.

No Paraná, o governo de Jaime Lerner (DEM), eleito em 1994 e reeleito em 1998, priorizou o consorciamento na área da saúde. Reproduzindo uma tendência que acontecia no plano dos municípios, indicou como secretário de saúde o médico Armando Raggio, que era seu assessor desde o período em que o então governador era prefeito de Curitiba, capital do 
estado, nos anos de 1980. Apesar do caráter conservador do partido do governador, o secretário tinha um passado de militância no movimento sanitarista, tendo sido ator relevante na criação do SUS. ${ }^{14}$ Com a autonomia dada pelo governador, o secretário adotou a concepção de distrito sanitário como parâmetro para a organização dos serviços em escala supramunicipal, visando ganhos de escala e efeitos redistributivos. Assim os CIS criados anteriormente se estabeleceram como experiências a serem difundidas para todo o estado.

A partir desse momento, o papel do governo estadual tornou-se progressivamente proeminente no fomento da cooperação intermunicipal. ${ }^{15}$ Conforme demonstrado no Quadro I, no período dos dois mandatos do governador Jaime Lerner (1995-2002), foram criados 17 CIS, ou seja, $65 \%$ do total, evidenciando a relevância da ação indutora do governo estadual na difusão dos CIS.

Nessa ação indutora, a Sesa utilizou-se do pessoal lotado nas RS - como indicado, anteriormente, defensores da cooperação intermunicipal na gestão da saúde - visando convencer os prefeitos a se consorciarem. Para tal, além dos argumentos e da difusão de informações, disponibilizou recursos financeiros e materiais extras para os municípios que se consorciassem. Mais que isso, a referência estabelecida pelo estado foi organizar os CIS com representação do governo estadual, criando as chamadas Comissões Bipartites. Houve reação dos municípios a essa presença do governo estadual na composição dos CIS, com o argumento de que seria uma ingerência na autonomia dos municípios (Keinert, 2001, p. 26). Reação sem resultados práticos, no entanto. Assim, o papel do governo estadual do Paraná na constituição dos CIS foi fundamental na criação e no funcionamento deles.

Alguns exemplos do papel indutor do governo estadual podem ser fornecidos. 0 primeiro é a própria criação do CIS Paraná Saúde, como salientado anteriormente, composto pela quase totalidade dos municípios do estado, com a função de gerir medicamentos. Até 1998 a política de programação, aquisição e distribuição de medicamentos estava centralizada no governo federal, através da Central de Medicamentos (Ceme). 0 processo de descentralização da gestão teve início com a implantação, em 1999, do Incentivo à Assistência Farmacêutica Básica (lafab), que transferia recursos financeiros aos municípios para a aquisição de medicamentos na atenção básica de saúde, permitindo a autonomia dos municípios na coordenação de ações e atividades relacionadas aos medicamentos. Um dos resultados foi a deficiência de escala na compra dos medicamentos, com consequente aumento de custos, uma vez que $79 \%$ dos municípios paranaenses são constituídos por uma população de menos de 20.000 habitantes. Com o objetivo de otimizar os recursos da assistência farmacêutica básica, em junho de 1999, cerca de 99\% dos municípios do estado do Paraná criaram o Consórcio Paraná Saúde, devido, fundamentalmente, ao papel exercido pelo governo estadual. Seria pouco provável que um número tão grande de municípios articulasse um esquema cooperativo de forma autônoma, dados os custos de transação envolvidos.

Outro exemplo do papel indutor do governo estadual foi a criação da Associação dos Consórcios e Associações Intermunicipais de Saúde do Paraná (Acispar), em 2001, cujo objetivo é representar o conjunto dos CIS no estado. 
No caso, o governo do estado apoiou fortemente a criação da associação, com objetivo de se relacionar de forma mais orgânica com o conjunto dos CIS do estado. Foi, por exemplo, por intermédio da Acispar que a Sesa implantou o Programa Estadual de Apoio aos Consórcios Intermunicipais de Saúde, visando, através de incentivos técnicos e financeiros, a ampliação da oferta de serviços de forma regionalizada. Sintoma da estreita cooperação entre o governo do estado e os CIS é o fato de que a sede da Acispar se localiza na antessala do gabinete do secretário estadual de saúde e, ainda, tem assento e voto no Conselho Estadual de Saúde.

Deve-se registrar, no entanto, que, se na maioria dos casos o governo do estado teve papel fundamental no momento de criação dos CIS, em vários deles, com o passar do tempo, a experiência local ganha dinâmica própria, com os municípios assumindo autonomia significativa na gestão dos mesmos.

\section{Path dependence, cooperação e territorialização}

A criação dos CIS suscita outro problema analítico, relacionado aos padrões territoriais adotados pelos consórcios. No caso do Paraná, esses padrões dependeram de duas formas de territorialização que antecederam à experiência dos CIS, ou seja, as RS e as AMs. Comparando os padrões das três modalidades de territorialização, nota-se que há uma reprodução exata do mapeamento de $18 \mathrm{CIS}$ ( $72 \%$ do total) com o padrão de determinadas RS e AMs. ${ }^{16}$ Isso significa que a composição da maioria dos CIS, em termos de municípios participantes, é réplica exata de determinadas RS e AMs.
Essa tendência de reprodução dos mesmos padrões territoriais para esquemas de cooperação de naturezas diferenciadas pode ser explicada em termos da lógica definida como path dependence, cujo significado Pierson (2004, p. 21) apresentou da seguinte maneira:

Na presença de feedback positivo, a probabilidade de novos passos na mesma trajetória aumenta com cada passo dado nesse percurso. Isso porque os benefícios relativos da atividade atual, comparados às opções anteriormente disponíveis, aumentam com o tempo. Dito de outra maneira, os custos de transação para uma alternativa previamente possível aumentam. ${ }^{17}$

No caso dos CIS no Paraná, formas de cooperação anteriores fortaleceram esquemas cooperativos futuros. Assim, a atuação dos policy entrepreneurs, dos políticos e das burocracias municipais não se deu num vazio. Sua ação ocorreu a partir de um padrão de institucionalização territorial fornecido pelas formas anteriores de regionalização. Isso significa que, ao longo do tempo, laços de colaboração estabelecidos entre grupos de municípios, num dado momento, facilitaram outras formas de cooperação posteriores, pois diminuíram os custos de transação entre os envolvidos. Ou seja, ao partir de esquemas cooperativos consolidados anteriormente, o número potencial de atores envolvidos na barganha pela criação de um CIS torna-se limitado e envolve pessoas que desenvolveram, ao longo de certo tempo, relações de confiança, gerando, assim, uma expectativa positiva sobre o cumprimento futuro de novos acordos celebrados (North, 1994, pp. 11-12).

Em geral, os policy entrepreneurs comprometidos com a difusão dos CIS procuraram 
convencer autoridades municipais, que já conviviam nas RS e nas AMs, a cooperarem na gestão da saúde. Buscaram, portanto, aproveitar-se de esquemas antecedentes de cooperação. Assim, a regionalização institucionalizada pelas RS e AMs facilitou a ação indutora desses policy entrepreneurs, já que forneceu suportes institucionais para a difusão da ideia dos CIS num contexto em que os atores cooperavam em outros âmbitos. Em geral, o governo estadual, através da sua burocracia, utilizou-se das RS como suporte institucional para induzir a cooperação entre municípios que já compunham cada regional; e, paralelamente, aqueles atores que atuavam na sociedade civil buscavam arregimentar os prefeitos para a criação dos CIS no âmbito do esquema territorial das AMs.

Apesar dos aspectos específicos relativos a cada caso, essa dinâmica incidiu sobre a constituição da quase totalidade dos CIS. Pode-se ressaltar, portanto, que a cooperação intermunicipal nos CIS foi facilitada ao se aproveitar de formas de cooperação anteriores.

\section{Os Consórcios Intermunicipais de Saúde e a competição político-eleitoral}

A cooperação intermunicipal é problemática na medida em que exige acordo entre atores que, pela lógica político-eleitoral, são concorrentes em potencial. ${ }^{18}$ Porém, as características objetivas da área da saúde tendem a demandar cooperação, pois a adequação da oferta dos serviços à necessidade de se gerar ganhos de escala exige organizar o sistema em um âmbito que extrapola os limites das divisões político- -territoriais definidas pelos municípios. Com os progressivos avanços científicos e a especialização cada vez mais presente na oferta dos serviços, a política de saúde apresenta aos governos o desafio de traduzir na oferta dos serviços o crescente cardápio de especialidades. Esse desafio exige cooperação entre governos para ser enfrentado com algum sucesso.

Como a sensibilidade do eleitorado para a qualidade da oferta dos serviços de saúde é alta, os prefeitos se veem constrangidos e incentivados a superar os obstáculos oriundos de suas diferenças político-partidárias com governantes de outros municípios. Isso pelo custo político de se negar acesso à população de um direito estabelecido constitucionalmente. No caso em questão, a incapacidade de cooperação pode produzir situações nas quais todos os principais atores políticos acabam perdendo.

Como se disse, os sanitaristas eram técnicos fazendo política, no sentido mais geral, mas também no sentido mais estrito de disputar espaços no aparato estatal. Ao se investirem da autoridade governamental, buscavam concretizar suas metas de regionalização, o que, no caso dos CIS, exigia certo insulamento da política eleitoral, já que os consórcios dependiam da cooperação de prefeitos potencialmente competidores na esfera político-eleitoral.

Diante do dilema apontado constatou-se, no Paraná, a tendência dos políticos se posicionarem de forma equidistante do processo de gestão dos CIS, reforçando a posição dos técnicos. ${ }^{19}$ Visavam, assim, deslocar a competição eleitoral para outras arenas.

Como esse processo de insulamento dos embates políticos é variavelmente precário, os CIS acabam apresentando equilíbrios mais ou menos instáveis, pois sempre está 
presente a possibilidade de partidarização das relações entre as lideranças municipais. Assim, além de fomentar o estabelecimento de acordos de cooperação entre os prefeitos, os policy entrepreneurs acabam tendo a função de mediar conflitos entre eles, visando garantir a prevalência dos pressupostos técnicos da cooperação.

Em alguns casos, a politização acabou redundando no fracasso da cooperação, como no caso do Cisamusep, com sede em Maringá, onde o Centro Regional de Especialidades era "aparelhado" por um deputado, no sentido da sua utilização para fins eleitorais, dificultando a cooperação dos municípios integrantes do CIS. Nas ocorrências de conflitos e impasses entre as autoridades políticas municipais, especificamente prefeitos, o papel de mediação exercido pelos policy entrepreneurs mostra-se como fundamental para a manutenção dos CIS.

\section{Considerações finais}

Com que o que foi apresentado anteriormente, podemos pontuar que o desenho das instituições estatais não é algo que possa ser tomado exclusivamente a partir de um modelo pronto. As relações federativas, como o caso da saúde mostra, são construídas tendo uma referência nacional, mas, ao mesmo tempo, dependem das características dos estados e dos municípios. Envolvem, portanto, relações governamentais, com aspectos cooperativos e competitivos, vertical e horizontalmente.
0 caso do Paraná mostrou que a cooperação dependeu tanto da ação autônoma de atores no plano dos municípios - especialmente dos menores -, como do papel indutor dos governos estaduais. Em ambos os níveis, a presença dos policy entrepreneurs foi crucial. Atuando com base em suportes institucionais fornecidos por esquemas de cooperação anteriores - as RS e as AMs -, esses atores, protagonistas do movimento sanitário, buscavam convencer os governantes da relevância da criação dos CIS.

Assim, a dependência de políticas públicas anteriores mostrou-se fundamental. Apropriando dos efeitos das ações de políticas públicas herdadas de governos passados, em termos de construção de capital social, a institucionalização dos CIS expressa, em grande medida, os padrões de territorialização estabelecidos pelas RS e AMs.

Nesse processo foi fundamental limitar a influência da lógica da competição eleitoral sobre a gestão da saúde. Estabeleceu-se, portanto, certo consenso, notadamente entre os prefeitos, de reforçar a posição dos técnicos na administração dos CIS.

Enfim, o processo de reestruturação das instituições estatais ou, mais especificamente, de definição de relações federativas que sejam virtuosas, exige experimentação e criatividade dos atores políticos. Nesse sentido, os resultados aqui expostos pretendem, além de jogar luz sobre um aspecto pouco explorado do federalismo brasileiro, auxiliar a busca de caminhos para enfrentar nossos desafios sociais. 


\section{Carlos Vasconcelos Rocha}

Pontifícia Universidade Católica de Minas Gerais, Pós-Graduação em Ciências Sociais. Belo Horizonte, MG/Brasil.

carocha@pucminas.br

\section{Notas}

(*) Este artigo é resultado de uma pesquisa mais ampla financiada pelo Conselho Nacional de Desenvolvimento Científico e Tecnológico (CNPq). Em parte, contou também com recursos de uma bolsa de pesquisa concedida pela Fundação de Amparo à Pesquisa do Estado de Minas Gerais (Fapemig). Agradeço o apoio dessas instituições. Além disso, é importante registrar a contribuição dos pareceristas desta revista, além dos comentários de colegas por ocasião da apresentação de partes da pesquisa no grupo de políticas públicas da Alacip e nos encontros da Rifipp. Naturalmente o resultado final aqui apresentado é de responsabilidade do autor. Agradeço prof. dr. José Flávio Morais Castro, da PUC Minas, pela elaboração dos mapas incluídos aqui.

(1) IBGE: Censo Demográfico 2010.

(2) Ao contrário do difundido anteriormente, foi se consolidando a ideia de que centralização e descentralização não são conceitos e práticas que se excluem mutuamente. São necessariamente complementares. Tal situação é definida por Hommes (1996, apud Tendler, 1999, p. 43) como o "paradoxo da descentralização": o esforço de descentralização demanda dimensionar o que vai ser centralizado, pois a qualidade desse processo depende das habilidades políticas do nível central de governo.

(3) Em um sistema eleitoral proporcional de lista aberta, como o brasileiro, a competição entre políticos locais é significativamente acirrada.

(4) As Conferências Nacionais de Saúde foram instituídas no final dos anos de 1930 e representam uma instância de participação de diversos segmentos sociais visando avaliar e propor diretrizes para a formulação da política de saúde. No período da democratização, nos anos de 1980, estabeleceram-se como importante espaço de ação dos movimentos sociais. A VIII Conferência estabeleceu as bases do SUS.

(5) De forma resumida e simplificadora, pode-se dizer que a decisão técnica é fundada num processo de ordem intelectual, baseada na análise racional, que busca levantar dados e construir uma visão geral de um problema e de suas alternativas, a partir de teorias existentes. As decisões políticas, por sua vez, surgem da interação de objetivos de grupos e indivíduos, que visam maximizar suas posições de poder, seja competindo, seja cooperando com outros atores. Essa distinção é claramente um instrumento metodológico, no sentido de um tipo ideal weberiano, já que na realidade não se pode distinguir claramente uma lógica da outra. Sobre o assunto, ver, por exemplo, Lindblom (1981).

(6) Traduzido do original: "efficiency and flexibility are subordinated to political accommodation and procedural guarantees". 
(7) Em 1999, por exemplo, Minas Gerais foi o estado com maior porcentagem de municípios consorciados na área da saúde, 92,4\% do total, sendo seguido pelo Paraná, com 77,6\%. O Brasil apresentava 31,5\% dos seus municípios consorciados (Cruz, 2001, p. 74). Para o caso de Minas Gerais, ver Rocha e Faria (2004) e Diniz Filho (2006).

(8) Esses municípios são: Campo Erê, Coronel Martins, Galvão, Jupiá, Novo Horizonte, São Bernardino, São Lourenço do Oeste.

(9) Traduzido do original: "Policy entrepreneurs can play a key role in identifying policy problems in ways that both attract the attention of decision makers and indicate appropriate policy responses [...] policy entrepreneurs must develop strategies for presenting their ideas to others. This is why policy entrepreneurs spend large amounts of time networking in and around government [...]. In so doing, they learn the 'world views' of various members of the policy-making community and make contacts that can help build their credibility. Making these contacts allows policy entrepreneurs to determine what arguments will persuade others to support their policy ideas".

(10) Uma evidência da relevância do movimento sanitário na organização dos municípios foi o seu protagonismo na criação do Conselho Nacional de Secretarias Municipais de Saúde (Conasems), em 1988, principal espaço de mobilização dos gestores municipais da saúde (Dowbor, 2014, p. 110). Aliás, evidência da relevância do caso do Paraná, é que de lá surge a proposta de criação do Conasems, a partir da experiência da Associação de Secretários Municipais de Saúde do Paraná, criada no início dos anos de 1980.

(11) As Regionais de Saúde (RS) foram fixadas pela Sesa, que definiu recortes territoriais agregando grupos de municípios, em espaços geográficos contínuos, com base em uma série de informações técnicas, visando induzir o mapeamento de regiões de saúde, como referência territorial para a organização das ações de saúde no estado.

(12) As AMs, criadas a partir do início da década de 1960 em diversos estados brasileiros, visam à promoção do desenvolvimento regional, através do planejamento e da cooperação intermunicipal.

(13) Além desses, sobram apenas mais dois municípios não consorciados: Cruzeiro do Oeste, com 21.149 habitantes e Palmas, com cerca de 47.000 habitantes, configurando casos bastante específicos. Desentendimentos políticos com os outros municípios geralmente explicam esses casos discrepantes, mesmo porque há certa instabilidade ao longo do tempo: em 2009, esses municípios estavam integrados, respectivamente, ao Cismerios e ao Conims e, por outro lado, nesse mesmo ano Pato Branco, sede atual do Conims, não estava participando de qualquer CIS (Paraná, 2009).

(14) Um dos dirigentes da Sesa daquele período, entrevistado para este trabalho, afirmou que Lerner dizia que: "a saúde fica com a esquerda, que ela resolve. Ainda mais que os sanitaristas dominam no governo federal, que tem recursos financeiros para a implementação de suas ideias". Desde o início dos anos de 1980 os sanitaristas ocupavam cargos de direção da área da saúde no governo federal (Dowbor, 2014, p. 94)

(15) Uma pesquisa de Lima e Pastrana (2000, pp. 14-15) demonstrou que diversos gestores de consórcios entrevistados revelaram ter recebido apoio estadual durante a sua fase de implementação. Para 53\% deles houve cooperação com as Secretarias Estaduais de Saúde, cujas formas mais comuns foram: "repasse de recursos, [...] cessão de equipamentos, estrutura física, recursos humanos e assessoria técnica", e ainda "fiscalização de contas, controle e avaliação". 
(16) Ver a demonstração dessa similitude em Rocha e Castro (2015).

(17) Traduzido do original: "In the presence of positive feedback, the probality of further steps along the same path increases with each move down that path. This is because the relative benefits of the current activity compared with once-possible options increases over time. To put it a different way, the costs of switching to some previously plausible alternative rise."

(18) Em um sistema eleitoral proporcional de lista aberta, como o brasileiro, a competição entre políticos locais é significativamente acirrada.

(19) Essa percepção foi compartilhada pela totalidade dos entrevistados. Um deles, que foi secretário estadual da saúde, afirmou que "os políticos davam autonomia aos técnicos, visando faturar com o bom funcionamento da política de saúde".

\section{Referências}

ABRUCIO, F. L. e SOARES, M. M. (2001). Redes Federativas no Brasil: Cooperação Intermunicipal no Grande $A B C$. São Paulo, Fundação Konrad Adenauer.

ACISPAR - Associação dos Consórcios e Associações Intermunicipais de Saúde do Paraná. (s/d.). Disponível em: http://acispar.com.br/Consorcios/consorcios-associados.php. Acesso em: 25 abr 2014.

ARRETCHE, M. T. S. (1996). Mitos da descentralização. Mais democracia e eficiência nas políticas públicas? Revista Brasileira de Ciências Sociais. São Paulo, v. 31, n. 11, pp. 44-66.

BRASIL. Ministério da Saúde (1997). O Consórcio e a Gestão Municipal em Saúde. Disponível em: http:// bvsms.saude.gov.br/bvs/publicacoes/cd05_14.pdf. Acesso em: 8 set 2015.

CRUZ, M. do C. M. T. (2001). Consórcios Intermunicipais: uma alternativa de integração regional ascendente. São Paulo, Pólis.

DANIEL, C. (2001). “Autonomia municipal e as relações com os estados e a União”. In: HOFMEISTER, W. e CARNEIRO, J. M. B. (orgs.). Federalismo na Alemanha e no Brasil. São Paulo, Fundação Konrad Adenauer.

DINIZ FILHO, P. R. (2006). Federalismo, indução estadual e cooperação intermunicipal: a experiência de dois Consórcios Intermunicipais de Saúde de Minas Gerais. Dissertação de Mestrado. Belo Horizonte, Pontifícia Universidade Católica de Minas Gerais.

DOWBOR, M. (2014). “Ocupando o Estado: análise da atuação do Movimento Sanitário nas décadas de 1970 e 1980." In: CARLOS, E.; OLIVEIRA, O. P. de e ROMÃO, W. de M. (orgs.). Sociedade civil e políticas públicas: atores e instituições no Brasil contemporâneo. Chapecó, Argos.

HOMMES, R. (1996). Conflicts and dilemmas of descentralization. Annual World Bank Conference on Development Economics. Washington D.C., World Bank, pp. 331-350.

KEINERT, T. M. M. (2001). Gestão estratégica de políticas públicas pelos governos subnacionais: análise da experiência "Municípios Saudáveis" e “Consórcios de Saúde" no Estado do Paraná. Relatório de Pesquisa. São Paulo, Esesp/FGV, n. 20. 
KINGDON, J. W. (1995). Agendas, alternatives, and public policies. Nova York, Harper Collins College Publishers.

LACZYNSKI, P. e TEIXEIRA, M. A. C. (2012). “Os limites de um consórcio intermunicipal em condições assimétricas de poder: o caso do Cinpra no Maranhão." In: FUNDAÇÃO KONRAD ADENAUER. Municípios e Estados: experiências com arranjos cooperativos. Rio de Janeiro, Fundação Konrad Adenauer.

LIMA, A. P. (1998). Os Consórcios Intermunicipais de Saúde e o Sistema Único de Saúde. Dissertação de Mestrado. Rio de Janeiro, Escola Nacional de Saúde Pública, Fundação Oswaldo Cruz.

(2000). Os consórcios intermunicipais de saúde e o Sistema Único de Saúde. Cadernos de Saúde Pública. Rio de Janeiro, v. 16, n. 4, pp. 985-996.

LIMA, A. P. G. e PASTRANA, R. (2000). Diagnóstico da situação atual de consórcios intermunicipais de saúde no Brasil. Relatório de Pesquisa. Brasília/DF, Ministério da Saúde/ Opas.

LIMA, L. D.; QUEIROZ, L. F. N.; MACHADO, C. V. e VIANA, A. L. (2012). Descentralização e regionalização: dinâmica e condicionantes da implantação do Pacto pela Saúde no Brasil. Ciência e saúde coletiva. Rio de Janeiro, v. 17, n. 7.

LINDBLOM, C. (1981). O processo de decisão política. Brasília/DF, Editora UnB.

MENDES, E. V. (1996). Uma agenda para a saúde. São Paulo, Hucitec.

MINTROM, M. (1997). Policy entrepreneurs and the diffusion of innovation. American Journal of Political Science. Wisconsin, v. 41, n. 3.

NORTH, D. C. (1992). Custos de transação, instituições e desempenho econômico. Rio de Janeiro, Instituto Liberal.

PARANÁ. Secretaria de Saúde do Estado do Paraná (2009). Plano Diretor de Regionalização: Hierarquização e regionalização da assistência à saúde no Estado do Paraná. Curitiba. Disponível em: http://www.saude.pr.gov.br/arquivos/File/PDR_atualizado_Edson.pdf. Acesso em: 8 set 2015.

PIERSON, P. (1995). Fragmented Welfare State: federal institutions and the development of social policy. Governance. Cambridge, v. 8, n. 4.

(2004). Politics in time: history, institutions, and social analisys. Princeton, Princeton University Press.

PUTNAM, R. (1996). Comunidade e democracia: a experiência da Itália moderna. Rio de Janeiro, Editora Fundação Getúlio Vargas.

ROCHA, C. V. e CASTRO, J. F. M. (2015). “Dilemas da territorialização na produção de políticas públicas: reflexões a partir do caso dos Consórcios Intermunicipais de Saúde em um estado brasileiro." In: FARIA, C. A. P. de; ROCHA, C. V.; FILGUEIRAS, C. A. C. e SOUKI, L. G. (orgs.). Políticas públicas na América Latina: territorialidades e interações com a sociedade. Porto Alegre, Cegov/UFRGS.

ROCHA, C. V. e FARIA, C. A. P. (2004). Cooperação Intermunicipal, reterritorialização da gestão pública e provisão de bens e serviços sociais no Brasil contemporâneo. Cadernos Metrópole. São Paulo, n. 11, pp. 73-105.

SANTOS, L. e ANDRADE, L. O. M. de (2009). SUS: o espaço da gestão inovada e dos consensos interfederativos. Campinas, Saberes. 
SCHARPF, F. W. (1988). The Joint-Decision Trap: Lessons from German Federalism and European Integration. Public Administration. Washington D.C., n. 66, pp. 239-278.

TENDLER, J. (1999). “Mitos da Reforma do Estado e da descentralização: conclusões de um estudo de caso no Brasil”. In: MELO, M. A. (org.). Reforma do Estado e Mudança Institucional no Brasil. Recife, Massangana.

VAZ, J. C. (1997). Consórcios Intermunicipais. Dicas Polis Ildesfes: ação administrativa - idéias para a ação municipal. Disponível em: http://bibliotecadigital.abong.org.br/bitstream/ handle/11465/1432/448.pdf?sequence=1\&isAllowed=y. Acesso em: 8 set 2015.

VIANA, A. L.; IBAÑEZ, N.; ELIAS, P. E. M.; LIMA, L. D.; ALBUQUERQUE, M. V. e IOZZI, F. L. (2008). Novas perspectivas para a regionalização da saúde. São Paulo em Perspectiva. São Paulo, v. 22, n. 1, pp. 92-106.

\section{Anexo I}

Consórcios Intermunicipais de Saúde do Paraná:

Associação Regional de Saúde do Sudoeste (ARSS)

Associação Intermunicipal de Saúde do Centro Oeste do Paraná (Assiscop)

Consórcio Intermunicipal de Saúde dos Campos Gerais (Cimsaúde)

Consórcio Intermunicipal de Saúde (CIS 22a R. S)

Consórcio Intermunicipal de Saúde da Região Centro Sul do Paraná (Amcespar)

Consórcio Intermunicipal de Saúde (Cisamerios)

Consórcio Intermunicipal de Saúde (Cisamunpar)

Consórcio Intermunicipal de Saúde do Setentrião Paranaense (Cisamusep)

Consórcio Intermunicipal de Saúde do Centro Oeste do Paraná (CIS Centro-Oeste)

Consórcio Intermunicipal de Saúde do Centro Noroeste do Paraná (Ciscenop)

Consórcio Intermunicipal de Saúde da Comunidade dos Municípios

da Região de Campo Mourão (Ciscomcam)

Consórcio Intermunicipal de Saúde Costa Oeste do Paraná (Ciscopar)

Consórcio Intermunicipal de Saúde Guarapuava/Pinhão (Cisgap)

Consórcio Intermunicipal de Saúde do Iguaçu (Cisi)

Consórcio Intermunicipal de Saúde do Médio Paranapanema (Cismepar)

Consórcio Intermunicipal de Saúde do Norte do Paraná (Cisnop)

Consórcio Intermunicipal de Saúde do Norte Pioneiro (Cisnorpi)

Consórcio Intermunicipal de Saúde do Oeste do Paraná (Cisop)

Consórcio Intermunicipal de Saúde do Vale do Iguaçu (Cisvali)

Consórcio Intermunicipal de Saúde do Vale do Paranapanema (Cisvap)

Consórcio Intermunicipal de Saúde do Vale do Ivaí e Região (Cisvir)

Consórcio Metropolitano de Saúde do Paraná (Comesp)

Consórcio Intermunicipal de Saúde (Conims)

Consórcio Intermunicipal de Saúde do Litoral do Paraná (Cislipa)

Consórcio Intermunicipal de Saúde (CIS Paraná Centro)

Consórcio Intergestores Paraná Saúde (Paraná Saúde)

Texto recebido em 23/dez/2015

Texto aprovado em 23/fev/2016 
